\title{
Primary leiomyosarcoma of the first metatarsal bone: A case report
}

\author{
D Singh MS(Ortho) \\ R Kumar MS(Ortho) \\ GG Kamau MMed(Ortho) \\ T Mmopelwa MMed(Ortho) \\ DK Mhembelo MMed(Ortho) \\ Mahalapye, Botswana (Southern Africa) \\ Corresponding author: \\ Dr Daljit Singh \\ Department of Orthopaedics \\ Mahalapye District Hospital \\ Mahalapye, Botswana \\ Email: drdaljitortho@gmail.com \\ Phone: +919855519990
}

Consultant Orthopaedic Surgeons, Department of Orthopaedics, Mahalapye District Hospital,

\begin{abstract}
Introduction: Primary leiomyosarcoma of bone is a rare entity which has never been reported in the foot. We report a case of primary leiomyosarcoma of metatarsal bone.

Case report: A 60-year-old male presented with a history of pain, progressively increasing swelling and a nonhealing ulcer over the dorsomedial aspect of his right foot. Plain radiograph showed an osteolytic, destructive lesion of the first metatarsal with involvement of surrounding soft tissue and bones. Magnetic resonance imaging showed a lesion that was hypointense on T1- and heterogeneous on T2-weighted images. Histology of the tumour with immunohistochemistry features aid in making the diagnosis of primary leiomyosarcoma of the first metatarsal bone, which was rare for this location.

Discussion: A brief review of the literature is done to determine the epidemiology, radiological and histological features and management of this tumour.

Conclusion: Primary leiomyosarcoma of bone is a rare tumour and should be kept in the differential diagnosis of primary malignant osteolytic, destructive neoplasms especially in the older age group

Level of evidence: therapeutic, IV
\end{abstract}

Key words: primary leiomyosarcoma of bone, metatarsal

http:/ / dx.doi.org/10.17159/2309-8309/2017/v16n1a6

\section{Introduction}

Primary leiomyosarcoma of bone is a rare tumour. ${ }^{1}$ Its most common location is in the metaphyseal region of the long bones, predominantly the femur and tibia. ${ }^{2}$ We report a case of primary leiomyosarcoma of first metatarsal, which to our knowledge, has never been reported at this site.

\section{Case report}

A 60-year-old male presented with nine-month history of pain and progressively increasing swelling over the dorsomedial aspect of the right foot. It started as a small painful swelling over the dorsum of the foot. The patient developed a non-healing fungating ulcer at the biopsy site during the course of disease (Figures $1 a$ and $b$ ). There was no history of trauma, fever or discharging sinus, and no history of any other swelling in the body. There was no history of radiation exposure. The patient was non-diabetic and did not present with any other systemic ailment.

On examination, a diffuse, hard swelling about $10 \times 15 \mathrm{~cm}$ was present over the dorsomedial aspect of the right foot. A fungating ulcer, about $4 \times 4 \mathrm{~cm}$ in size, was present over the swelling. There was full range of motion of the ankle. Examination of the chest and abdomen was normal.

Plain radiograph of the foot showed a poorly defined lytic lesion with complete destruction of the first metatarsal bone extending into the surrounding tissues, second metatarsal, medial and middle cuneiform (Figure 2). 

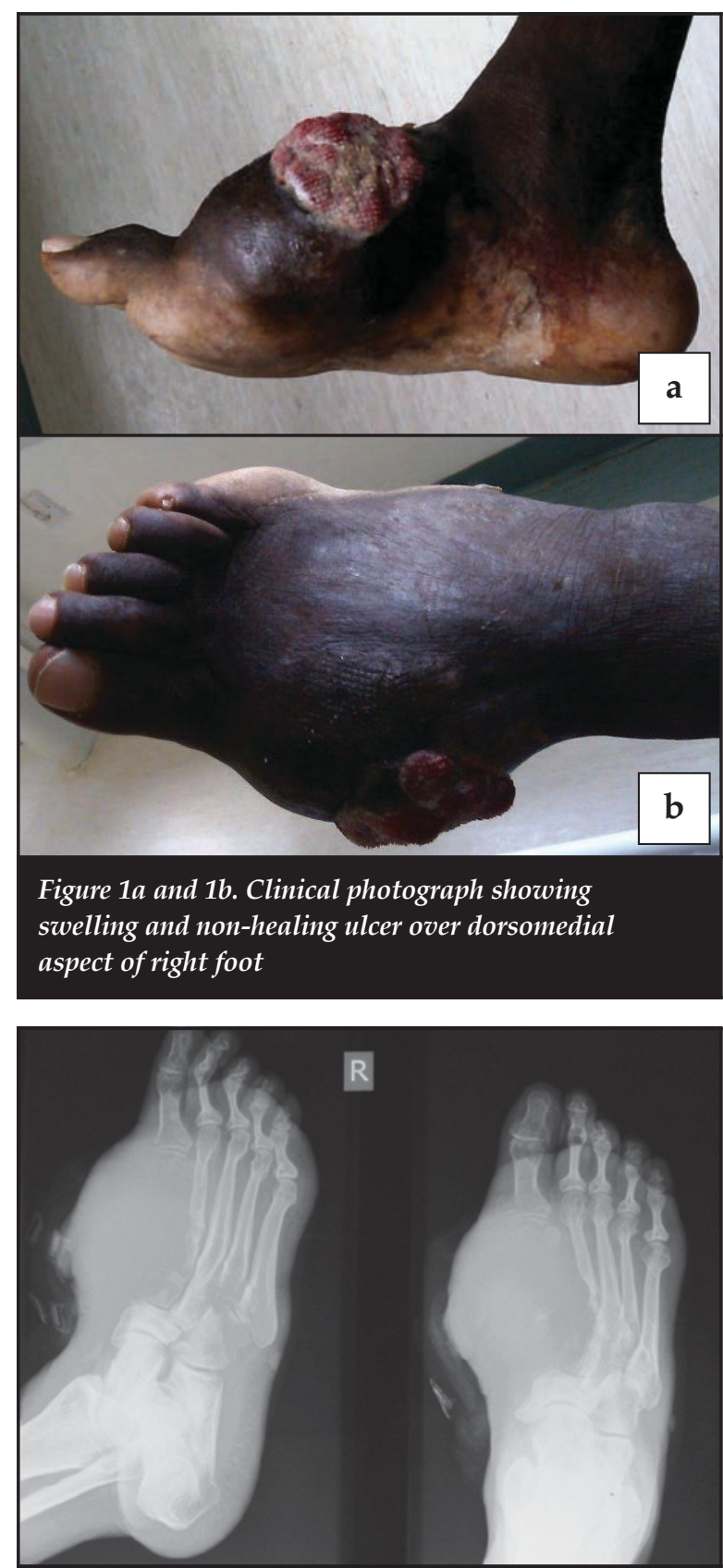

Figure 2. Plain radiograph anteroposterior and oblique view of foot showing osteolytic lesion of first

metatarsal with involvement of surrounding soft tissue and bones

Magnetic resonance imaging of the lesion showed it to be hypointense on T1-weighted image and heterogeneous on T2-weighted image with iso- and hypertense areas (Figures 3 and 4). Computed tomography of the chest and abdomen including pelvis was normal.

Routine haematological and biochemical investigations showed no abnormality.

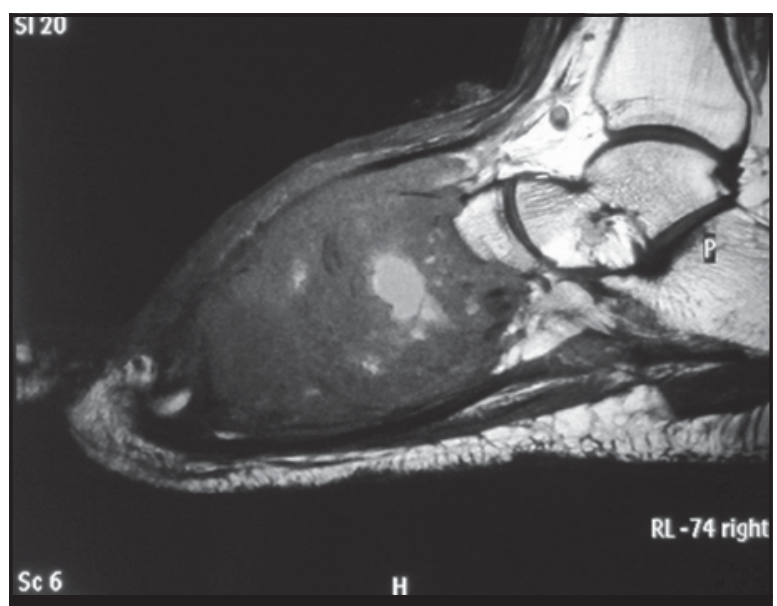

Figure 3. MRI of right foot showing hypointense lesion on T1-weighted image

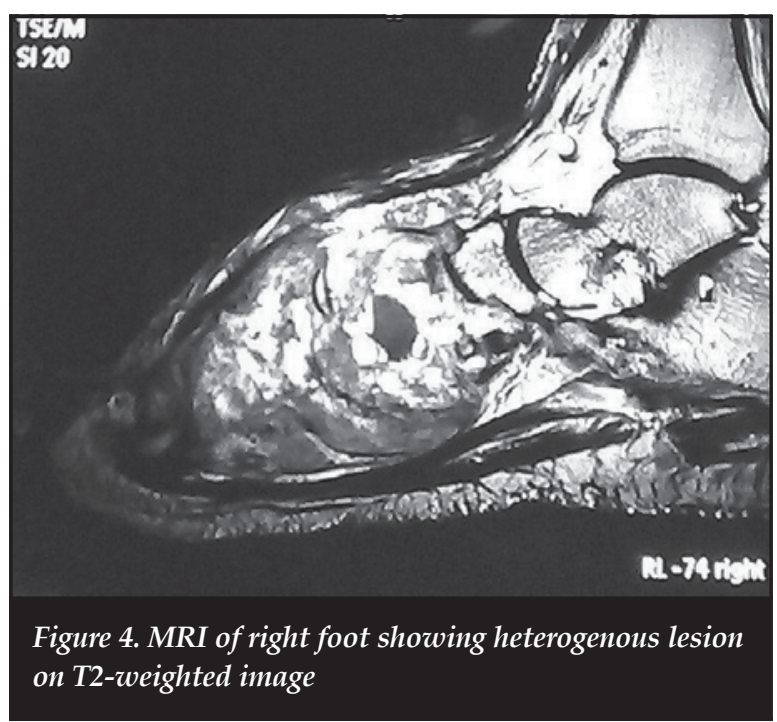

The histopathological examination of the biopsy specimen showed malignant tumour composed of eosinophilic spindle cells with vesicular, ovoid to cigar-shaped nuclei, arranged in fascicles. The tumour cells showed abundant eosinophilic cytoplasm. The tumour showed high mitotic activity (27 mitotic figures/HPF) including abnormal mitotic figures with necrotic area (Figure 5). The morphological features are consistent with leiomyosarcoma. The surgical margins were free of tumour.

On immunohistochemistry, the tumour cells showed focal positive staining for smooth muscle actin (SMA) and diffuse positive staining for vimentin. AE1/AE3, desmin and epithelial membrane antigen staining were negative (Figures 6 and 7). The immunohistochemical features confirmed the morphological diagnosis of leiomyosarcoma. The patient was admitted and explained the nature of the disease. Below-knee amputation was performed after taking consent from the patient. Histopathological examination of the amputation specimen reconfirmed the diagnosis. 

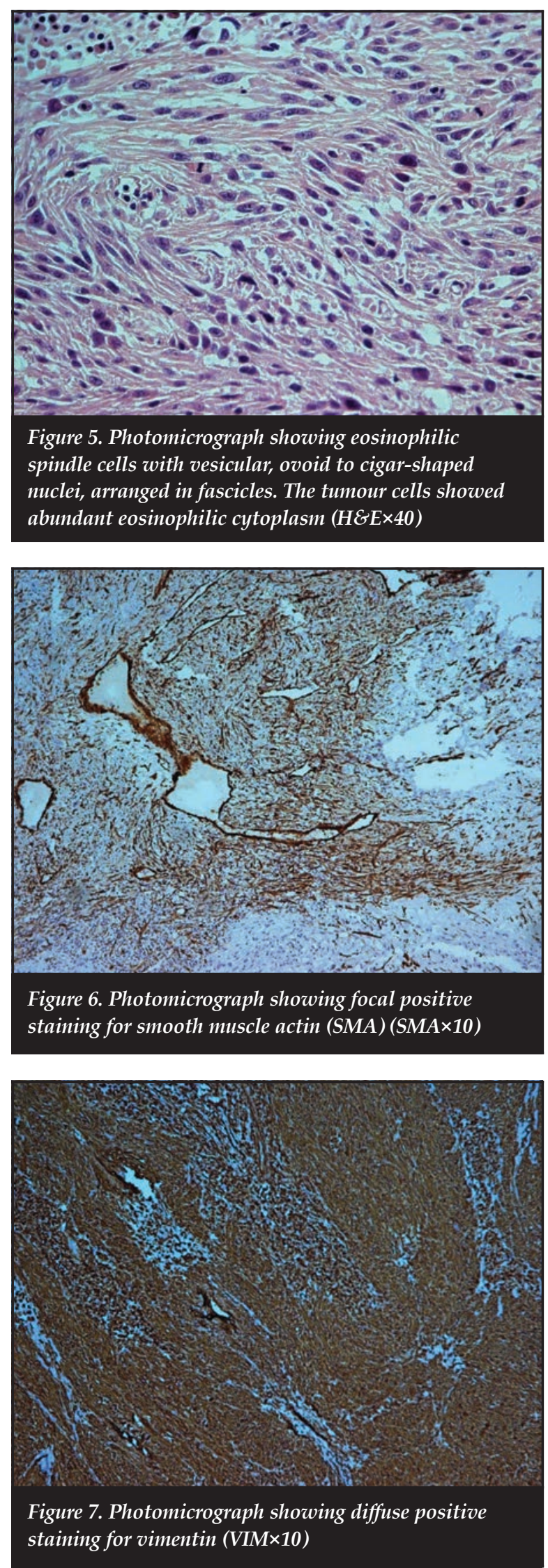

The surgical margins were free of tumour. The patient was put on a programme of physiotherapy to train the amputated stump for a period of 4 weeks. He was back at work using a below-knee prosthesis 4 months after his initial presentation to the institute, and is still on regular follow-up to check for recurrence or metastasis. The patient was informed that the data would be submitted for publication, to which he gave his consent.

\section{Discussion}

Leiomyosarcomas are malignant smooth muscle tumours, occurring most frequently in the retroperitoneum, uterus, gastrointestinal tract and soft tissues of the extremities. ${ }^{1}$

Primary leiomyosarcoma of bone is a rare distinct variety first described in 1965 by Evans and Sanerkin. ${ }^{17}$ The most common sites involved are the long bones of the femur, tibia and humerus but other sites are also involved including craniofacial skeleton, pelvic bones, radius, clavicle, rib, sternum, phalanx and vertebra. ${ }^{1-17}$ There have been a few isolated cases in the literature where the tumour has involved the bones of the foot, including one case of os calcis and two of talus. ${ }^{12,18,19}$ The primary leiomyosarcoma involving metatarsal bone has, to our knowledge, never been reported in the literature.

Pain is the most common presenting symptom. There is no general agreement in literature regarding sex predilection of the tumour but it appears to have an equal gender distribution or slight male predominance. ${ }^{2-16}$ The age of presentation in most of the series ranges from 9-80 years, with the mean age in the fourth decade. ${ }^{2-6,10,11,14,15}$ The case in our study was a 60 -year-old male.

Radiographically, the lesion of primary leiomyosarcoma of bone is purely osteolytic and may show various degrees of aggressive features such endosteal scalloping, indistinct margins, lack of sclerosis, cortical breakthrough and extension into the surrounding soft tissue, whether in flat or long bones. ${ }^{34,8,10,15}$ The lesion may show a moth-eaten, permeative or geographical pattern of bone destruction depending on the aggressiveness of the tumour. ${ }^{8}$ Radiographic appearance is not typical and mimics any other primary or secondary malignant tumour. The differential diagnosis on plain radiograph may be lymphoma, malignant fibrous histiocytoma, plasmacytoma, fibrosarcoma, Ewing's sarcoma, osteolytic osteogenic sarcoma and metastatic carcinoma. ${ }^{8,10,15,20}$ The lesion in the present case was expansile, osteolytic with indistinct margins, extending into the surrounding tissue and associated with lack of sclerosis.

MRI of leiomyosarcoma of bone is often inconclusive. Sundaram et al. noted that on MRI the tumour is hypotense on T1-weighted images but show heterogenous signal intensity on $\mathrm{T} 2$ weighted images associated with areas of iso- and hypointensity in relation to fat. ${ }^{10}$ We also found the lesion to be hypointense on T1-weighted image and heterogenous on T2-weighted image.

The diagnosis of leiomyosarcoma of bone was established by its characteristic microscopic appearance and supported by the positive immunohistochemical staining for actin antibodies and typical electron microscopic features. All the leiomyosarcomas described in bone show the same features: a sheet-like proliferation of spindle cells arranged in intersecting fascicles with elongated cigar-shaped or pleomorphic nuclei, frequent mitosis and necrosis. ${ }^{4,810,15}$ Among immunohistochemical markers, most of the 
studies have described expression of smooth muscle actin (SMA), desmin, or vimentin in an objective identification of smooth muscle origin..$^{2,-13,15,18,19}$ Electron microscopy showed definite smooth muscle differentiation including cytoplasmic filaments with dense bodies, basement membranes and pinocytotic vesicles. ${ }^{45,7,7,11,12,18}$

According to Young, immunohistochemistry allows the histological diagnosis to be made without the need to resort to ultrastructural studies. ${ }^{5}$

The differential diagnosis on histology includes fibrosarcoma, malignant fibrous histiocytoma, myofibrosarcoma, metastatic carcinoma and osteosarcoma. ${ }^{15,20}$

The microscopy in the present case showed eosinophilic spindle cells with vesicular, ovoid to cigar-shaped nuclei, arranged in fascicles. The tumour cells showed high mitotic activity with necrotic areas. Immunohistochemistry showed focal positive staining to SMA and diffuse positive staining to vimentin in tumour cells.

Surgical is the treatment of choice for leiomyosarcoma of bone. Surgical excision with wide margins remains the gold standard for curative management. Chemotherapy, either neoadjuvant or adjuvant, and radiotherapy do not provide an improved prognosis over a simple ablative surgical procedure. ${ }^{8,1,14,15}$ We planned for below-knee amputation to obtain wide, tumour-free margins.

\section{Conclusion}

Primary leiomyosarcoma of bone is rare and should be kept in the differential diagnosis of primary malignant osteolytic, destructive neoplasms, especially in the older age group. Vascular leiomyosarcoma of peripheral veins is another rare possibility although more common sites are inferior vena cava, pulmonary arteries and iliac veins. ${ }^{21,22}$ Histopathology evaluation with immunohistochemistry analysis is helpful in reaching the accurate diagnosis. Treatment is primarily surgical with limited benefit from neoadjuvant and adjuvant therapies.

\section{Compliance with Ethics Guidelines}

The authors declare that no benefits of any form have been received from a commercial party related directly or indirectly to the subject of this article.

The patient was informed that the data would be submitted for publication, to which he gave his consent.

\section{References}

1. Campanacci M. Bone and Soft Tissue Tumors: Clinical Features, Imaging, Pathology and Treatment. $2^{\text {nd }}$ edition. 1999.

2. Brewer P, Sumathi V, Grimer RJ, Carter SR, Tillman RM, Abudu A, and Jeys L. Primary leiomyosarcoma of bone: analysis of prognosis. Sarcoma. 2012. Article ID 636849, 4 pages doi:10.1155/2012/636849.

3. Berlin O, Angervall L, Kindblom LG, Berlin IC, Stener B. Primary leiomyosarcoma of bone. A clinical, radiographic, pathologicanatomic, and prognostic study of 16 cases. Skeletal Radiology. 1987;16(5):364-76.

4. Myers JL, Arocho J, Bernreuter W, Dunham W, Mazur MT. Leiomyosarcoma of bone. A clinicopathologic, immunohistochemical, and ultrastructural study of five cases. Cancer. 1991;67(4):1051-56.
5. Young MP, Freemont AJ. Primary leiomyosarcoma of bone. Histopathology. 1991;19(3):257-62.

6. Jundt G, Moll C, Nidecker A, Schilt R, Remagen W. Primary leiomyosarcoma of bone: Report of eight cases. Human Pathology. November 1994; 25(11):1205-12.

7. Khoddami M, B'edard YC, Bel RSl, and Kandel RA. Primary leiomyosarcoma of bone: report of seven cases and review of the literature. Archives of Pathology and Laboratory Medicine. 1996;120(7):671-75.

8. Antonescu C R, Erlendson RA. Primary leiomyosarcoma of bone: a clinicopathologic, immunohistochemical, and ultrastructural study of 33 patients and a literature review. American Journal of Surgical Pathology. November 1997;21(11):1281-94.

9. Wirbel RJ, Verelst S, Hanselmann R, Remberger K, Kubale K, Mutschler WE. Primary leiomyosarcoma of bone: clinicopathologic, immunohistochemical and molecular biologic aspects. Ann Surg Oncol. 1998;5:635-41.

10. Sundaram M, Akduman I, White LM, McDonald DJ, Kandel R, Janney C. Primary leiomyosarcoma of bone. AJR Am J Roentgenol. 1999 Mar;172(3):771-76.

11. Jeanrot $C$, Ouaknine $M$, Anract $P$, Carlioz A, Forest $M$, Tomeno B. Primary leiomyosarcoma of bone. Report of 5 anatomoclinical cases and review of the literature. Rev Chir Orthop Reparatrice Appar Mot. 2000 Feb;86(1):63-73.

12. Bouaziz MC, Chaabane S, Mrad K, Oueslati S, Bellassoued A, Ladeb MF, Rhomdhane KB. Primary leiomyosarcoma of bone: report of 4 cases. Journal of Computer Assisted Tomography. March/April 2005;29(2):254-59.

13. Atalar H, Gunay C, Yildiz Y, Saglik Y. Primary leiomyosarcoma of bone: a report on three patients. Clin Imaging. 2008 JulAug;32(4):321-25.

14. Adelani MA, Schultenover SJ, Holt GE, Cates JMM. Primary leiomyosarcoma of extragnathic bone: clinicopathologic features and reevaluation of prognosis. Archives of Pathology and Laboratory Medicine. 2009;133(9):1448-56.

15. Rekhi B, Kaur A, Puri A, Desai S, Jambhekar NA. Primary leiomyosarcoma of bone - a clinicopathologic study of 8 uncommon cases with immunohistochemical analysis and clinical outcomes. Annals of Diagnostic Pathology. 2011;15:147-56.

16. Weiss SW, Goldblum JR. Enzinger and Weiss's soft tissue tumors. $4^{\text {th }}$ edition Philadelphia: Mosby-Harcot, 2001.

17. Evans DM, Sanerkin NG. Primary leiomyosarcoma of bone. Journal of Pathology and Bacteriology. 1965;90(1):348-50.

18. Marymont JV, Clanton TO. Leiomyosarcoma of the os calcis. Foot Ankle. $1990 \mathrm{Feb}$;10(4):239-42.

19. Trojani M, Coquet M, Peres P, Coindre JM, Ragni R, MeugeMoraw C. Primary leiomyosarcoma of bone. A case with ultrastructural study. Review of the literature. Sem Hop. 1983 Apr;59(15):1179-83.

20. Greenspan A, Jundt G, Remagen W. Differential diagnosis in orthopaedic oncology. $2^{\text {nd }}$ edition. 1997;446-50.

21. Kevorkian J, Cento JP. Leiomyosarcoma of large arteries and veins. Surgery 1973;73:39.

22. Dzsinich C, Gloviczki P, van Heerden JA, et al. Primary venous leiomyosarcoma: a rare but lethal disease. Journal of Vascular Surgery. 1992;15(4):595-603.

This article is also available online on the SAOA website (www.saoa.org.za) and the SciELO website (www.scielo.org.za). Follow the directions on the Contents page of this journal to access it. 